\title{
Isolation and Characterization of an Acetamiprid Degrading Bacteria from Cultivated Soils of North Gujarat Region
}

\author{
Dipika Pandya $^{1 *}$, Vikram Solanki ${ }^{1}$, S. G. Patel $^{2}$ and S. A. Bhatt ${ }^{1}$ \\ ${ }^{1}$ Department of Life Science, Hemchandracharya North Gujarat University, Patan, India \\ ${ }^{2}$ Department of Plant Pathology, College of Agriculture, NAU, Bharuch Campus, India
}

*Corresponding author

Keywords

Pesticide,

Biodegradation,

Acetamiprid

Article Info

Accepted:

15 January 2021

Available Online:

10 February 2021

\section{A B S T R A C T}

Microorganisms can survive in polluted environment, which develop potential to degrade substances that are harmful to the environment. Environmental pollution caused by the leaking of chemical fertilizers and pesticides to surface and groundwater, causing serious environmental and social problems throughout the world. Soil samples have been taken from vegetables and cotton plantation that has history of using pesticide for controlling pests. Isolation of these microorganisms has been carried out by using serially diluted sample by streaking on suitable nutrient media. The positive isolates growing at different concentration of pesticides in the nutrient media have been characterized with respect to their morphology and biochemical reactions. The pesticide degradation study is carried out by using potential isolates grown at different pesticide level in the growth media and the degradation has been studied at different concentration during one week of incubation. The degradation products are analyzed by GCMS. The results of pesticide degradation are discussed.

\section{Introduction}

Pesticide is a substance or mixture of substances which is used for preventing, destroying and also repelling pests. Pesticide may be biological agent or chemical substance used for pest control. Pest include insects, weeds, birds, fishes and plant pathogens that destroy property and vegetation, spread disease or are vector for disease $(1.3,6)$ Pesticides are most useful in pest control but there are drawbacks of these such as potential toxicity to humans and other animals.

Due to uncontrolled use of pesticide, environment has become contaminated and polluted. $(2,9,8,12,13)$ There are two main reasons for these compounds to persist in 
nature. First, the condition necessary for their biodegradation may not be present. Microorganisms that are capable for degrading these toxic compound may be absent at contaminated site.

If the necessary microorganisms are present some limiting factors such as a nutrient storage or some unfavorable environmental condition for biodegradation of contaminant and second is that the compound which is used for pest control may be recalcitrant or resistant to biodegradation. However, there are some microorganisms which can survive in the soil contaminated with pesticide. So identification and characterization of these bacteria is important to study about its potential for degradation of pesticides. Acetamiprid is an organic compound with the chemical formula $\mathrm{C}_{10} \mathrm{H}_{11} \mathrm{ClN}_{4}$ (see figure 1 for structure). It is an odorless neonicotinoid insecticide. It is intended to control sucking insects on crop such as leafy vegetables and cotton. It is also used for cherry farming to control its fruit fly. Acetamiprid is classified as human carcinogen. The insecticidal activity of neonicotinoid is due to their competitive engagements against the post synaptic acetylcholine (nicotinic) receptor in the central nervous system of insects. It is soluble in most organic solvents and shows increased solubility in water. Neonicotinoid pesticides comprise a fairly new and widely used category of organic compounds which cover about the $17 \%$ of global pesticide market and therefore these may be threat to aquatic and terrestrial environment.

Considering the potential of microorganisms to adapt to the environment and capacity to use these as nutrients for growth, their presence is expected at these sites of large use of pesticides for certain crops. Some microorganisms may exist that can degrade the pesticide and also have potential application in bioremediation.

\section{Materials and Methods}

\section{Collection of soil sample}

Total eight samples collected from vegetable field at different villages in Patan and Mehsana district having history of repeated pesticide application. All the samples are collected in sterile zipper polyethylene bags and stored at $4^{0} \mathrm{C}$ before processing.

\section{Media}

Burkes Mineral Medium (BMM) enriched with acetamiprid is used for isolation and characterization of acetamiprid degrading bacteria.(4,5,7,10,11) The BMM has the following composition in (g/l) $\mathrm{K}_{2} \mathrm{HPO}_{4}, 0.2 \mathrm{~g}$; $\mathrm{KH}_{2} \mathrm{PO}_{4}, 0.8 \mathrm{~g} ; \mathrm{MgSO}_{4}, 0.2 \mathrm{~g} ; \mathrm{CaCl}_{6} \mathrm{H}_{2} \mathrm{O}$; $\left(\mathrm{NH}_{4}\right)_{2} \mathrm{SO}_{4}, 0.2$; Yeast extract $0.02 \%, 0.2 \mathrm{~g}$; Glucose 1\% (Shivamaiah and kennedy) for the isolation of bacteria. Luria-Bertani(LB) broth is used according to the manufacturer instructions (HI-MEDIA)

\section{Soil Analysis}

Soil physical analysis has been determined as per methods described in "Methods of Soil Analysis-Part II, $2^{\text {nd }}$ ed. Am. Soc. Agron., Madison Wisconsin, USA.

\section{Isolation and characterization of bacteria}

Soil bacteria capable of degrading acetamiprid have been isolated from cultivated soil treated with pesticide

From $10 \%$ soil suspension serially diluted up to $10^{-3}, 0.1 \mathrm{ml}$ is inoculated in BMM agar containing 20,30, 50,100 of acetamiprid by spread plate technique. A total of eight different soil samples collected from various sites in Patan and Mehsana districts. Where cotton and in some vegetable like chili is grown. Inoculated plates are incubated at $37^{\circ} \mathrm{C}$ 
for several days till isolated colonies developed. Pure cultures are prepared and studied for their colony and cell morphology. These are characterized biochemically.

The potential strains of bacteria which showed good growth on BMM agar with $50 \mathrm{ppm}$ of pesticide were selected for identification. The identification has been carried out using Biolog' (MicroLog3 4.20.05) on the basis of sole carbon source utilization and biochemical analysis results are listed in table 3 .

\section{Degradation study}

Inoculum is prepared in Luria broth by inoculation of bacteria and incubated on rotary shaker at $180 \mathrm{rpm}, 28^{\circ} \mathrm{C}$ temperature for 4 7days. $10 \mathrm{ml}$ of inoculum is added in $90 \mathrm{ml}$ of BMM which contain 50 ppm acetamiprid pesticide. This is incubated at $28^{\circ} \mathrm{C} \& 120$ rpm and after 48 hours $10 \mathrm{ml}$ broth is taken as sample. This is homogenized. To this 3-4 drop of concentrated hydrochloric acid is added and mixed well. Equal volume (10ml) Hexane ethyl acetate mixture $(20: 80)$ is added and subjected to vortex for $5 \mathrm{~min}$. Then centrifuged at $2000 \mathrm{rpm}$ for 25 minutes. The Organic phase is removed and kept at $4^{0} \mathrm{C}$ and immediately subjected to moisture remove. Sample is analyzed through Gas chromatograph and mass spectroscopy.

\section{Gas chromatography with Mass Spectroscopy}

Perkin Elmer Auto System XL(courtesy: ISTAR, VV nagar) is used to analyze the degraded pesticide sample after incubation in presence of potential degrading bacteria. The incubated sample is subjected to hexane: ethyl acetate extraction. One microliter of sample has been injected to GCMS under following operative conditions:

Injector temp: $250^{\circ} \mathrm{C}$
Oven temp: $70^{\circ} \mathrm{C}$

Time: 5 min

Temperature increase rate: $10^{0} \mathrm{C}$ for min up to $280^{\circ} \mathrm{C}$.

Holding time of sample: $20 \mathrm{~min}$

E1 source temp: $250^{\circ} \mathrm{C}$

Column identification: PE-5MS, $30 \mathrm{~mm} \times 250 \mu \varnothing$ and $0.250 \mu$ thickness.

Mass range: 30 to $650 \mathrm{AMU}$

Split ratio: 6:660

\section{Results and Discussion}

In the present study bacterial isolates have been worked out for acetamiprid degradation from the field soils of Patan and Mehsana districts. Soil samples are collected from the cropping soils containing mainly the cotton field and vegetable fields (cultivating chilli) which have history of pesticide use to control pests. Soil physical characteristics are worked out to determine the texture by sieve analysis. The soils are mostly silt loam. The soil textural properties are depicted in table 1. Acetamiprid degrading bacteria have been isolated on Burkes Mineral Medium (BMM) incorporated with different concentrations of acetamiprid. Isolated colony has been studied for their morphological characters (see table2) and biochemical characteristics (see table3).

The potential isolates which showed resistance against different concentrations of pesticide are studied for their degradative potential of acetamiprid. The active culture of the isolate has been used to inoculate the BMM broth containing 50 ppm of acetamiprid. 
Table.1 Soil texture

\begin{tabular}{|c|c|c|c|}
\hline Soil sample & $\begin{array}{c}\text { Coarse } \\
\text { Sand }\end{array}$ & Fine Sand & Silt + Clay \\
\hline K1 & 40.20 & 43.50 & 16.30 \\
\hline K2 & 41.86 & 36.78 & 21.10 \\
\hline K3 & 37.80 & 32.18 & 29.72 \\
\hline K4 & 41.11 & 28.07 & 30.46 \\
\hline M1 & 60.10 & 35.40 & 04.09 \\
\hline M2 & 24.01 & 44.62 & 30.46 \\
\hline M3 & 45.95 & 33.99 & 19.73 \\
\hline M3 & 22.26 & 55.17 & 22.07 \\
\hline
\end{tabular}

Table.2 Morphological characteristics

\begin{tabular}{|c|c|}
\hline Colony character & Ct \\
\hline Size & Medium \\
\hline Shape & Round \\
\hline Margin & Undulated \\
\hline Elevation & Raised \\
\hline Surface & Smooth \\
\hline Pigment & Yellow \\
\hline Consistency & Moist \\
\hline Transparency & Opaque \\
\hline
\end{tabular}

Table.3 Biochemical characteristics of isolate

\begin{tabular}{|c|c|c|}
\hline Sr. No. & Biochemical test & Result \\
\hline $\mathbf{1}$ & Carbohydrate fermentation & \\
\hline $\mathbf{a}$ & Maltose & Acid and gas \\
\hline $\mathbf{b}$ & Lactose & Negative \\
\hline $\mathbf{c}$ & Mannitol & Only acid \\
\hline $\mathbf{d}$ & Glucose & Negative \\
\hline $\mathbf{e}$ & Sucrose & Negative \\
\hline $\mathbf{2}$ & Methyl red & Positive \\
\hline $\mathbf{3}$ & Indole production & Negative \\
\hline $\mathbf{4}$ & $\mathrm{H}_{2}$ S production & Negative \\
\hline $\mathbf{5}$ & Gelatin hydrolysis & Negative \\
\hline $\mathbf{6}$ & Catalase & Positive \\
\hline $\mathbf{7}$ & Dehydrogenase & Positive \\
\hline $\mathbf{8}$ & Casein utilization & Negative \\
\hline $\mathbf{9}$ & Lipid hydrolysis & Positive \\
\hline $\mathbf{1 0}$ & Starch utilization & Positive \\
\hline $\mathbf{1 1}$ & Citrate utilization & Positive \\
\hline $\mathbf{1 2}$ & Urea hydrolysis & Negative \\
\hline
\end{tabular}


Table.4 Chromatogram result of Pantoea dispersa

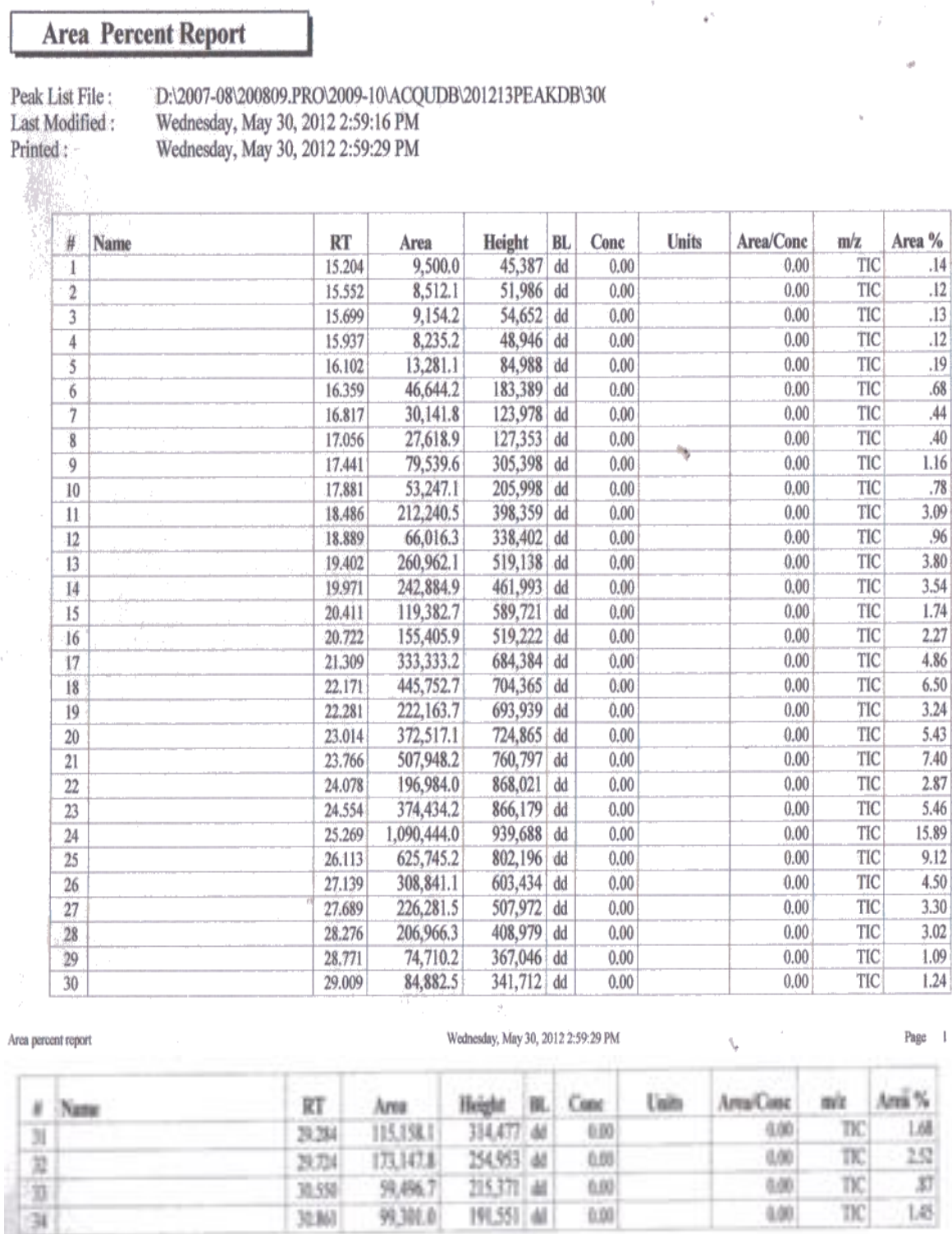


Table.5 Possible metabolites after degradation

\begin{tabular}{|c|c|c|c|c|c|c|}
\hline Hit & REV & for & Compolind Name & MW Formula & CAS & Liberay. \\
\hline 1 & 764 & 612 & S.NDACENE 17 DOONE, $2,5,6$ TETRAHYDRO $3,3,5$-TETRAM & 242 C1611602 & 555917178 & Nist: \\
\hline 2 & 719 & 382 & 1HHNDENE 3.ETHYL-A (1NETHMLTHAL & 186,614416 & 141400852 & Nis: \\
\hline 3. & 708 & 397 & 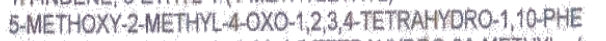 & $2420144402 \mathrm{~N}$ & 100022706.90 & Nist \\
\hline 4 & 702. & 337 & 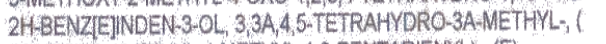 & $200 \mathrm{C} 141160$ & 71805919 & Nis: \\
\hline 5 & 702 & 354 & BENZENE (2ETHALANETHM-13PENTADIENYL), (E) & $186 \mathrm{C} 44 \mathrm{H} 18$ & 74663.675 & Nist \\
\hline 6 & 684 & 314 & WHANDENE, 4 S SRIMETHYL & 158 C12414 & 2177.45 .8 & Nist: \\
\hline 7 & 679 & 415 & 1(2H) PHENANTHRENONE, $3,4,9,10$ TETRAHYDRO 7 NETHOX & 228 C 1541602 & 14427613 & Nist: \\
\hline 8 & 666 & 353 & ISOLONGIFOLENE, $4,5,900$ OEHYRO & 200 c15H20 & 1000151550 & Nist \\
\hline 9 & 661 & 305 & BEN2ENE, $1,2 B I S(1-B U T E N 3 \times)$ & 186.614418 & $100016273.9^{\circ}$ & Nist: \\
\hline 10 & 655 & 340 & 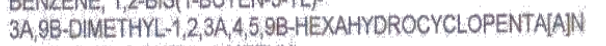 & 2140154100 & $1000194-130$ & Nis: \\
\hline 11 & 647 & 312 & 1HANDENE 3-BUTHL-1-METHVL. & 186 614418 & $111400-844$ & Nis: \\
\hline 12 & 617 & 376 & PHENANTHRENE, 9BUTML-1,2,3,5,6,8,8CTAHYORO. & 2426184126 & 1670329.0 & Nist \\
\hline 13 & 677 & 507 & 2(1H) PHENANTHRENONE, $3,4,49,9,10,10 A$ HEXALNDRO $1,1,4$ & $\begin{array}{l}242618+26 \\
242617+220\end{array}$ & $61141-103$ & Nist \\
\hline 14 & 607 & 47 & 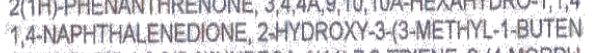 & & 4042391 & Nist \\
\hline $15:$ & 600 & 304 & 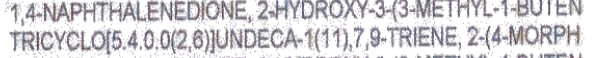 & $\begin{array}{l}242 \mathrm{C} 15 \mathrm{H} 1403 \\
229 \mathrm{Cl}+4190 \mathrm{~N}\end{array}$ & 0042991 & Nbs \\
\hline 16 & 587 & 432 & 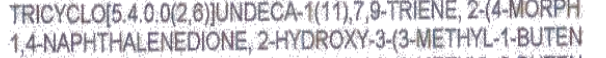 & $229 \mathrm{CH} H 190 \mathrm{~N}$ & 24296.524 & Nist \\
\hline 17 & 584 & 431 & & $242615 H_{1403}$ & 4042804 & Nbs: \\
\hline 18. & 581 & 450 & 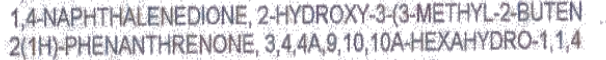 & 242 C15H1408 & 84797 & Nbs \\
\hline 19 & $560^{\circ}$ & 389 & 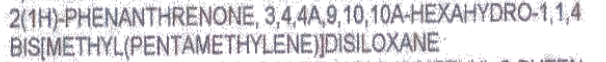 & 2420174220 & 55902904 & Nist \\
\hline 20 & 568 & 399 & 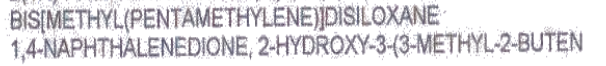 & 242 9121260si2 & $100024573 \% 70$ & Nist \\
\hline & & & & 242015141403 & 84797 & Mbs \\
\hline
\end{tabular}

Table.6 Possible metabolites after degradation

\begin{tabular}{|c|c|c|c|c|c|c|}
\hline 腊 & REV & to & Compound Name - & MW. Formula & CAS & Lotory \\
\hline 1 & 798 & 314 & SHETHYL-2-ETHENYLCYCLOHEXANE-CARBOXYLCACD & 108 C10H1602 & 160144556 & Nist \\
\hline 2 & 757 & 424 & BCYCLOR2,1 1 HEPTANE, 7,7.DIMETHYL-2NETHMENE. & 136 crovit & 4714841 & Nos \\
\hline 3 & 750 & 530 & (HEOCLOVENE-AI), DHYYRO & $200 \mathrm{c} 15420$ & $1000152 \cdot 83.6$ & Nist \\
\hline 4 & 745 & 572 & 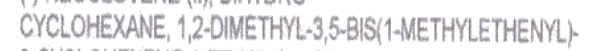 & 192 C14h24 & 62337.989 & Nos \\
\hline 5 & 736. & 510 & 3.CYCLOHEXENE-OETHANOL, BETA,4OMIMTHYL, $\left[R-R^{*}, R^{*}\right]$ & 15461044180 & 13835.304 & Nist \\
\hline 6 & 737 & 519 & CYCLOPROPANECARBOXYLIC ACID, 2,2.0MLTHM-3.2METH & $302 \mathrm{C12H2603}$ & 28444006 & Nist \\
\hline 7 & 736 & 594 & $2,10,14$ HEXADECATETRAENOIC ACD $, 3,7,14,15$-TETRAMET & 318 C24H\$402 & 4220788.5 & Noss \\
\hline 8 & 733 & 597 & ACETICACIO, AMETHYLS-2,6,6-TRMETHYLYCLOHEX-1EN & 236 C1542602 & 1000190960.91 & Nist \\
\hline$g$ & 733 & 545 & ACETIC ACID, 1 AMETHLS.3260.TRMETHMLYCLOHEX.2EN & $238 \mathrm{C} 15 \mathrm{H} 2602$ & $1000192-15.81$ & Nist \\
\hline 10 & 730 & 523 & 2AZIDOMETHM-1,3,3-TRMETHML-CYCLOHEXENE & 779 ClOHIN & $1000180-847^{2}$ & Nist \\
\hline 11 & 790 & 491 & 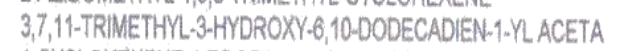 & 28201740003 & 1000144127000 & Nist \\
\hline 12 & 729 & 523 & 1-CYCLOHEXENE-1PROPANAL, 26,6.TRMETHYL. & $180 \mathrm{C12H} 2 \mathrm{CO}$ & 35477442 & Nist \\
\hline 13 & $72 B$ & $\$ 13$ & 4,8,13-CYCLOTETRADECATRIENE $1,3-D O O L, 1,5,8$ TRIMETHML. & 300 C20H3402 & 722078.2 & Nbs \\
\hline 14 & 720 & 545 & 2(1,4,4 TRMETHYCYCLOHEX2-EN-1-V) SETHML P-TOLUENES & 322 c18420035 & $1000195-70-2800$ & Nist \\
\hline 15 & 726 & 539 & CYCLOHEXANE, $1,1,2$ TRIMETHML,3,5.BIS(1METHMLTHENY) & $206 \mathrm{C}+5 \mathrm{H} 26$ & 62387.97 .7 & Nist \\
\hline 16 & 725 & 585 & DHHORO-ALPHA NETHYLONONE & $208 \mathrm{C} 14 \mathrm{H} 240$ & $56763-645$ & Nist \\
\hline 17 & 721 & 517 & CVCLOHEXANE, 1;2DIMETHMS,5-BS(4-METHMETHENM \& I & $182614+24$ & 74800.550 & Nist \\
\hline 16 & 719 & 490 & CYCLOHEXANOL, 2NETHYLS์ 11METHMETHENM) & 154 C10H780 & 619012 & Nos \\
\hline 19 & 713 & 446 & 2(FENCH2.YL)FENCHANE & 274 C20H34 & $100010583-1000$ & Nist \\
\hline 20 & 711 & 421 & C(14A)HOMO-27-NOR-14.BETA.GAMUACERAN-3.ALPHA.OL & $428 \mathrm{C} 3 \mathrm{NH}^{2} 20$ & 24739080 & Nist \\
\hline
\end{tabular}


Fig.1 Structure of acetamiprid

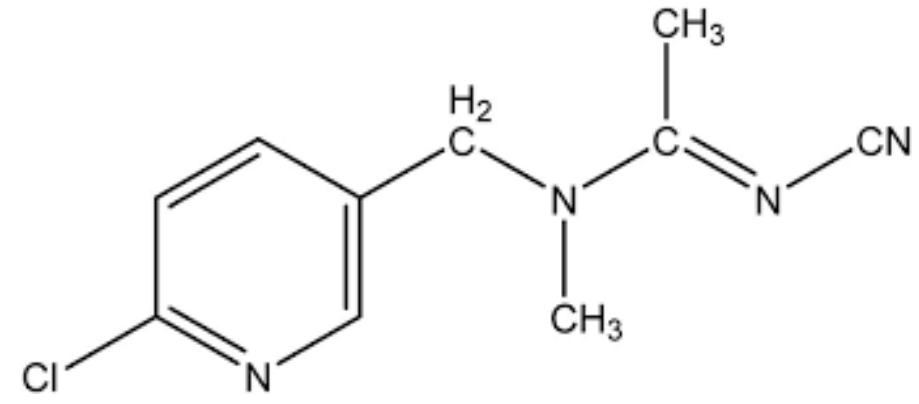

Fig.2 Chromatogram of standard sample of acetamaprid pesticide

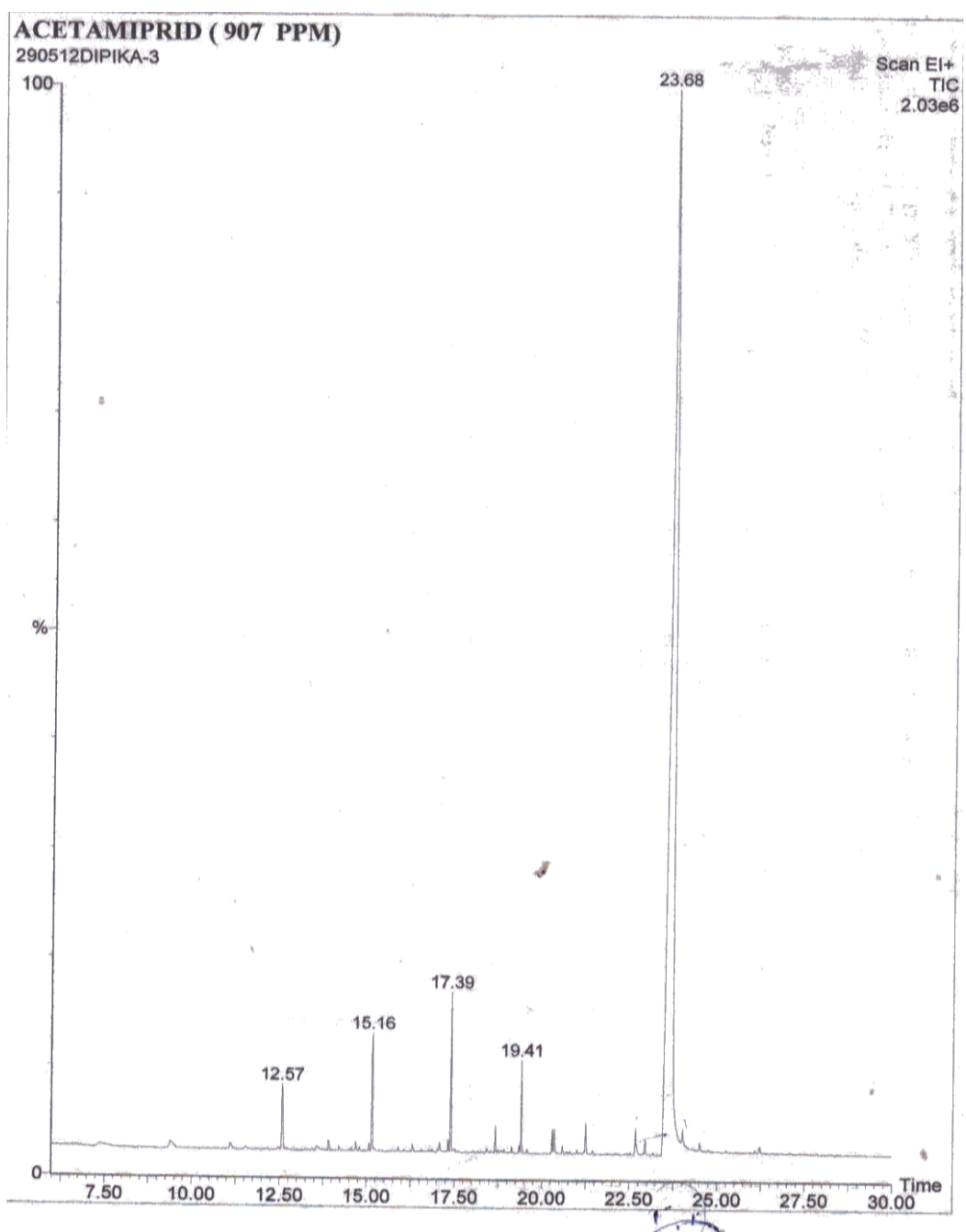


Int.J.Curr.Microbiol.App.Sci (2021) 10(02): 1557-1568

Fig.3 Chromatogram for Pantoea dispersa

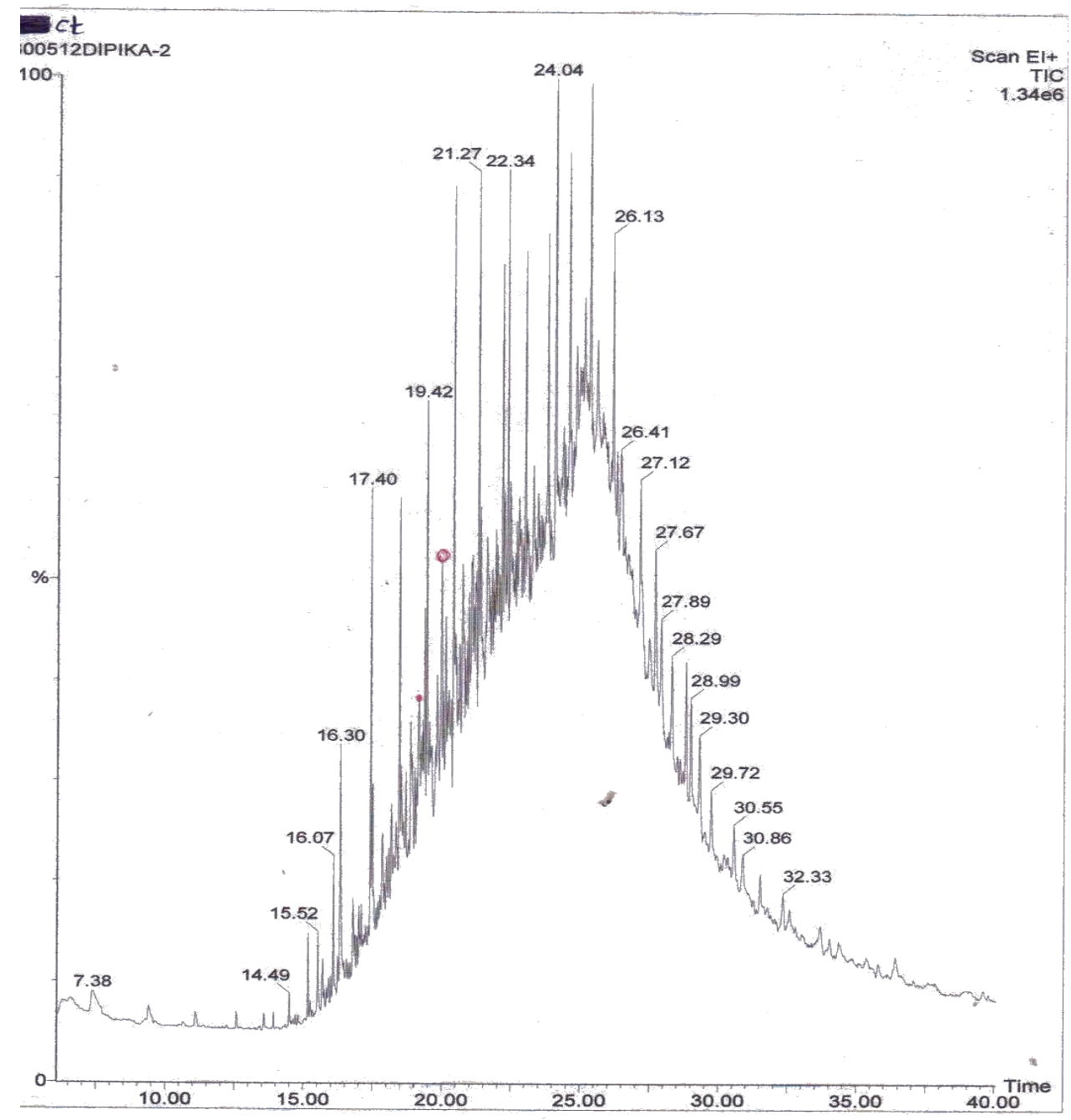


Fig.4 Mass spectra analysis of degradation products of Acetamiprid for pantoea dispersa (A)

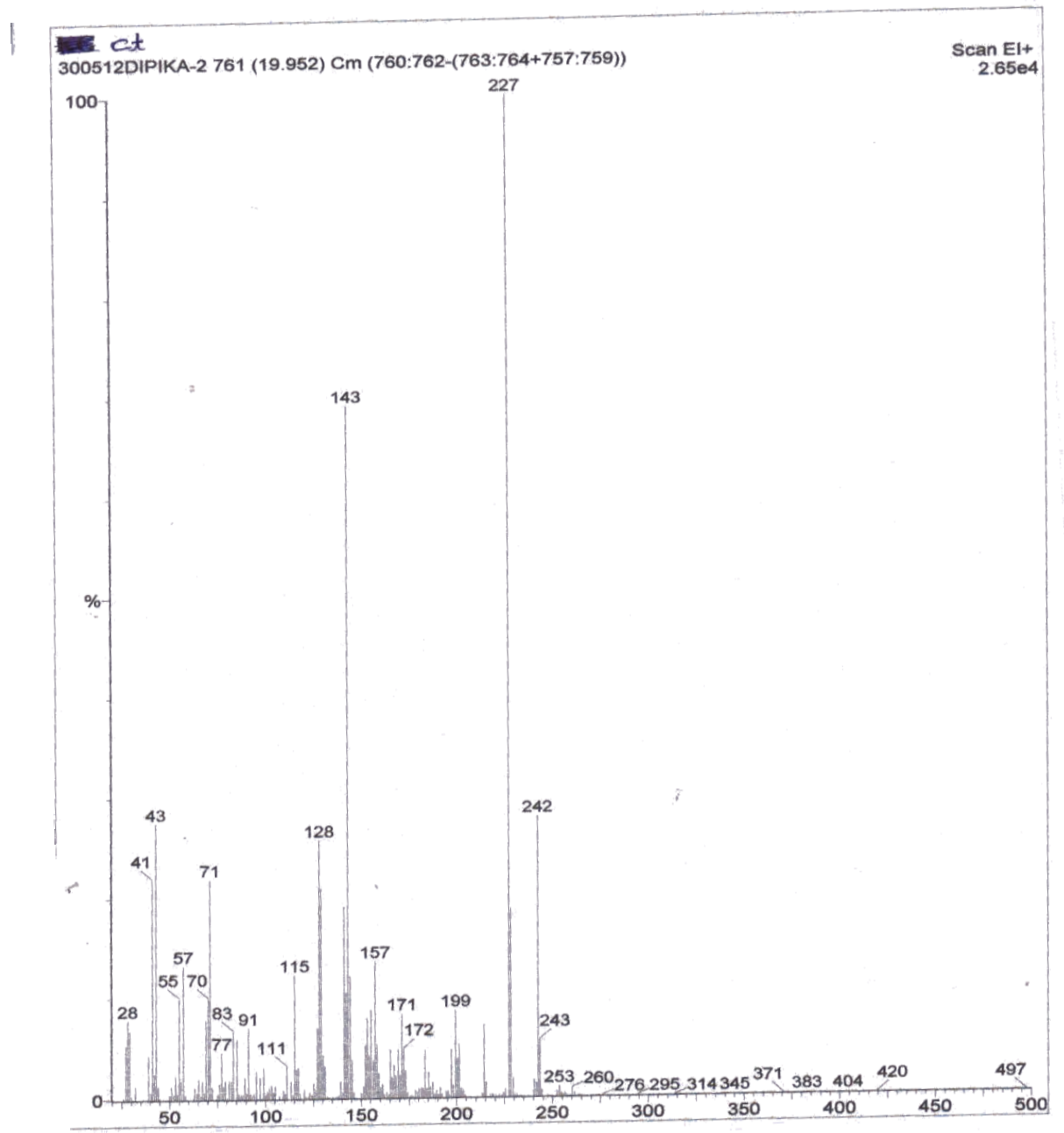


Fig.5 Mass spectra analysis of degradation products of Acetamiprid for pantoea dispersa (B)

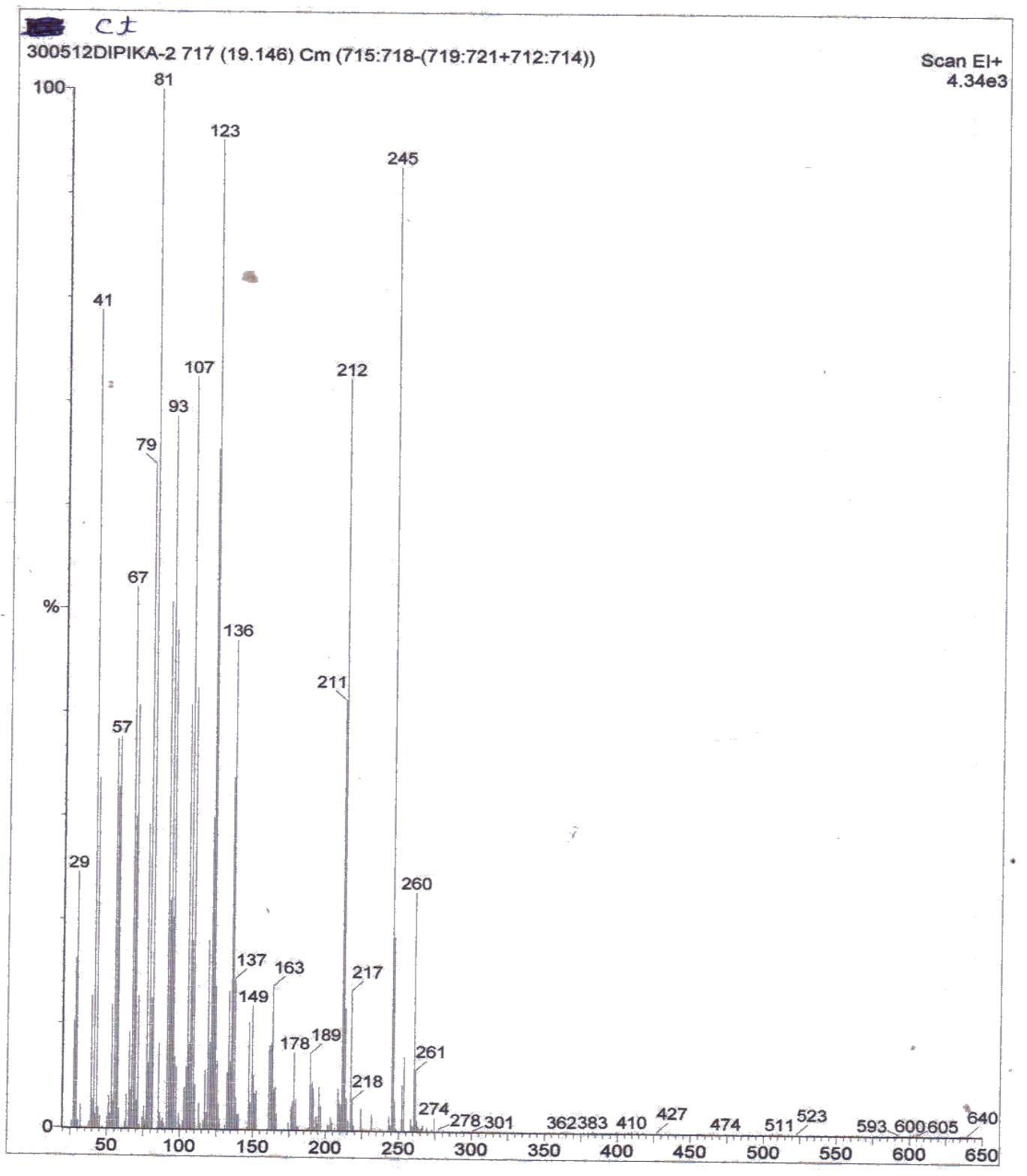

The broth was incubated at $26{ }^{\circ} \mathrm{C}$ at $150 \mathrm{rpm}$ for 7 days. After incubation the pesticide was extracted in organic solvent and subjected to GCMS analysis.

The potential culture has also been subjected to Biolog analysis for their identification. On the basis of utilization of Hydroxy -L-Proline as sole carbon, the organism has been identified as Pantoea dispersa. This bacteria is a plant pathogen causing disease in plants. The capacity of this organism to degrade acetamiprid is significant because this would increase its virulence. The results of GCMS analysis of the degradation product of this organism is depicted in the figures showing the GCMS data (Fig. 2-5). The peaks shown by the degradation analysis clearly indicates that the pesticide has been completely degraded in seven days of incubation. The 
degradation products are also listed in the figures. The $16 \mathrm{~S}$ rRNA analysis also confirmed that the isolate is Pantoea dispersa.

These isolate completely degraded 50ppm concentration of acetamiprid pesticide. The degradation products are measured by GCMS analysis. Standard sample of acetamiprid gives pick at $23.68 \mathrm{~min}$ (retention time). At this retention time the degraded products do not give any pick. This means the pesticide is degraded completely. The possible metabolites and chromatogram of all the isolates are in the listed in table 4 to 6 .

Among the isolates which are recorded as potential degraders of acetamiprid have been identified on the basis of sole carbon source utilization by Biolog System (Make and model).These isolates belong to genus Pantoea and Bacillus. These isolates have been isolated from soil contaminated with the pesticide. This pesticide is used for the protection of crops, vegetables namely cotton and chilly in the districts of Patan and Mehsana. The major degradation products in case of both are S-Indacene-1,7-Dione, 2,3,5,6Tetrahydro-3,3,5,5-tetram and Decane,3cyclohexyl. With possible minor products like Cyclohexane,1,1'-(1-Ethyl-1,2 - Ethanediyl) Bis, 1,4 - Napthalenedione, 2 - Hydroxy - 3 (3 - Methyl - 2 - Butane),1(2H)Phenanthirenone,3,4,9,10-Tetrahydro-7-

Methox,Bis[Methyl(Pentamethylene)]Disiloxa ne, etc.

\section{References}

Eurek Alert, (2009). New 'green' pesticides are first to exploit plant defenses in battle of the fungi. The benefits of pesticides: A story worth telling. Purdue.edu

Frazar C., (2000). The bioremediation and phytoremediation of pesticide contamination sites national network of environmental studies(NWEMS) fellow, Washington DC.

Hackenberg D., (2007). Letter from David Hackenberg to American growers from March 14, 2007 Plattform ilmkernnen -Australia.

Jeschke P. and Nauen R., (2008). Review, Neonicotinoids - from zero to hero in Insecticide chemistry, Pesticide Management Science, 64:1084-1098.

Kagabu, S. and Mejed, S., (1995). Stability comparison of imidacloprid and related compounds under simulated sunlight hydrolysis conditions and oxygen. Biosci. Biotechnol. Biochem., 59, 980985.

Kagabu, S. (1997). Chloronicotinyl insecticides - discovery, application and future perspective. Review Toxicology 1, 75-129.

Kamrin, MA., (1997). Pesticide Profile: toxicity, environmental impact and fate. CRC Press. Cornell University. Toxicity of pesticide. Pesticide fact sheet and tutorial, module 4. Pesticide Safety Education Program. Retrieved on 2007, 10-10.

Kaufman, D. D., (1974). Degradation of pesticides by soil microorganism. pages 133-202 in: Pesticides in soil and water. W. D. Guenzi. ed. soil. sci. Am, Madison. WI.

M.A.Bezerraa,. R.E. Santelli.., E.P. Oliveiraa, L. S. Villar and L. A. Escaleiraa, (2008).

Review: Response surface methodology (RSM) as a tool for optimization in analytical chemistry, Talanta, 76, 965977.

10. Matsuda K., Buckingham S. D., Kleier D., Rauh J.J., Grauso M. and Sattelle D.B., (2001). Neonicotinoids: insecticides acting on insect nicotinic acetylcholine Receptors, TRENDS in Pharmacological Sciences, 22(11), 573-580. 
Palmer, WE, Bromely, PT, and Brandenburg, RL, (2007). Wildlife \& pesticides Peanuts. North Carolina Cooperative Extension Service.

Pignatello J. J., Oliveros E. and MacKay A., (2006). Advanced Oxidation Processes for Organic Contaminant Destruction
Based on the Fenton Reaction and Related Chemistry, Environmental Science and Technology, 36:1 84.

Peter H.A., Sneath, Nicholas, S. Mair, M. Elisabeth Sharpe, John G. Holt. Bergey's manual of systematic Bacteriology Vol. 2.

\section{How to cite this article:}

Dipika Pandya, Vikram Solanki, S. G. Patel and Bhatt, S. A. 2021. Isolation and Characterization of an Acetamiprid Degrading Bacteria from Cultivated Soils of North Gujarat Region. Int.J.Curr.Microbiol.App.Sci. 10(02): 1557-1568.

doi: https://doi.org/10.20546/ijcmas.2021.1002.185 